\title{
Daily coffee consumption and prevalence of nonmelanoma skin cancer in Caucasian women
}

\author{
Ernest L. Abel ${ }^{a, b}$, Susan O. Hendrix ${ }^{a, c}$, S. Gene McNeeley ${ }^{a, c}$, \\ Karen C. Johnson ${ }^{d}$, Carol A. Rosenberg ${ }^{e}$, Yasmin Mossavar-Rahmani', \\ Mara Vitolins ${ }^{\mathrm{g}}$ and Michael Kruger ${ }^{\mathrm{a}, \mathrm{b}}$
}

The purpose of this study was to assess the relationship between daily coffee consumption and nonmelanoma skin cancer. This study was a cross-sectional analysis of women enrolled in the Women's Health Initiative Observational Study $(n=93676)$. As nearly all cases of self-reported nonmelanoma skin cancer occurred among Caucasian women (97.8\%), we focused our analyses on this group. Compared with nondrinkers, women drinking only caffeinated coffee on a daily basis had a $10.8 \%$ lower prevalence of nonmelanoma skin cancer. Consumption of six or more cups of caffeinated coffee per day was associated with a $36 \%$ reduction in nonmelanoma skin cancer. After adjusting for various demographic and life style variables, daily consumption of six or more cups was associated with a $30 \%$ reduced prevalence of nonmelanoma skin cancer. In contrast to caffeinated coffee, daily consumption of decaffeinated coffee was not associated with a significant change in self-reported nonmelanoma skin cancer for Caucasian women. Daily caffeinated coffee consumption was associated with a

\section{Introduction}

Most epidemiological studies examining associations between coffee drinking and cancer have focused primarily on cancers of the bladder, pancreas, colorectum and breast. While some of these studies have reported an increased association for these cancers among coffee drinkers compared with nondrinkers, results have been inconsistent. The absence of a dose or duration-related association in studies reporting statistically significant associations also precludes concluding that a strong relationship exists between coffee consumption and nonmelanoma skin cancer (NMSG) (e.g. Tavani and LaVecchia, 2000; Michels et al., 2002).

Nonmelanoma skin cancer is one of the most common types of cancer in the United States (Strom and Yamamura, 1997). Lifetime probability of developing this form of cancer in the United States is one in five (Tavani and LaVecchia, 2000). About 1.3 million new cases are diagnosed each year (Tavani and LaVecchia, 2000). While mortality is low (about $0.1 \%$ ) owing to low metastasis (Von Domarus and Stevens, 1984), morbidity and treatment costs are considerable (Johnson et al., 1984). Although studies in animals have reported dose-related decreased prevalence of nonmelanoma skin cancer in Caucasian women. European Journal of Cancer Prevention 16:446-452 (c) 2007 Lippincott Williams \& Wilkins.

European Journal of Cancer Prevention 2007, 16:446-452

Keywords: coffee, menopause, nonmelanoma skin cancer, women

Departments of abstetrics \& Gynecology, ' ${ }^{\text {a }}$ sychology, 'Women's Health Initiative, Wayne State University, Detroit, Michigan, 'University of Tennessee Health Science Center, Memphis, Tennessee, ${ }^{e}$ Department of Medicine, Evanston Northwestern Healthcare, Evanston, Illinois, 'Department of Epidemiology and Population Health, Albert Einstein College of Medicine, New York, New York and gepartment of Public Health Sciences, Wake University School of Medicine, Winston-Salem, North Carolina, USA

Correspondence to Dr Ernest L. Abel, PhD, C.S. Mott Center for Human Growth \& Development, 275 E. Hancock, Detroit, MI 48201, USA Tel: + 1313577 1068; fax: + 13135778554 ; e-mail: eabel@wayne.edu

Received 25 April 2006 Accepted 28 June 2006

strong evidence that caffeine inhibits skin cancers and other tumors (Wang et al., 1991, 1992, 1994; Huang et al., 1997), we are unaware of epidemiological studies examining the relationship between caffeine and NMSC, with the exception of two small studies that found a decrease in NMSC among coffee drinkers (Jacobsen et al., 1986; Corona et al., 2001).

The current study examined the relationship between caffeinated and decaffeinated coffee consumption and NMSC among more than 90000 postmenopausal women participating in the Women's Health Initiative (WHI) Observational Study, taking into account confounding factors previously found to be associated with NMSC (Schottenfeld, 1996; Rosenberg et al., 2004).

\section{Methods}

\section{Study population}

Postmenopausal women, 50-79 years of age, enrolled in the WHI Observational Study between 1993 and 1998, at 40 clinical centers throughout the United States who were either ineligible for the WHI clinical trial or declined to participate in it, were studied. Detailed 
eligibility criteria and study methods have been previously described in detail [The Women's Health Initiative (WHI) Study Group, 1998], as well as baseline characteristics of participants (Langer et al., 2003). Briefly, women of diverse ethnic backgrounds, representing the major ethnic groups in the United States, who volunteered to participate, were eligible if postmenopausal at time of enrollment. At time of enrollment, women completed screening and enrollment questionnaires that included questions about demographic and lifestyle variables, coffee consumption and history of skin cancer. The questionnaire categorized coffee and tea consumption each day, as none, one, two to three, four to five, or six or more cups per day. Respondents were also asked whether they consumed caffeinated coffee, decaffeinated coffee, or tea for the past 3 months.

\section{Data analysis}

Data analyses were based on information obtained at the baseline visit. Previous history of NMSG was based on self-report. A priori variables included in the analyses were those known or suspected as being associated with NMSC (Schottenfeld, 1996; Rosenberg et al., 2004) using the same criteria or cut points as Rosenberg et al. (2004). These included age at screening, ethnicity (native American, Asian, Black/African-American, Hispanic, White/Caucasian, other), latitude of the clinic where patients were enrolled (Southern $<35^{\circ} \mathrm{N}$, Middle $35-40^{\circ} \mathrm{N}$; Northern $>40^{\circ} \mathrm{N}$ ); body mass index (BMI) $\left(<25\right.$ or $\left.\geq 25 \mathrm{~kg} / \mathrm{m}^{2}\right)$, history of smoking (current, past, nonsmoker), alcohol use (nondrinker, past drinker, $<7$ or $\geq 7$ drinks per week), menopausal hormone therapy (current users, past users, defined as those receiving therapy for $>3$ months but not receiving therapy at time of interview and nonusers), education (highest grade completed: < 12 years, high school, some college, college degree or postgraduate school), household income $(<\$ 20000, \$ 20000-49000,>\$ 50000)$, percentage daily calories from fat $(<30.0,30.0-35.0,35.1-40.0$, $>40.0$ ), physical activity (METs/week) and $\beta$-carotene intake $(\mu \mathrm{g})$; the latter two were categorized into four levels based on the 25th percentile cut-points $(0-25$, $26-50,51-75,>75)$, having a current healthcare provider and marital status (never married, divorced or separated, presently married). As in the Rosenberg et al. (2004) study, we considered women reporting daily energy intakes of $<600$ or $>5000 \mathrm{kcal} / \mathrm{day}$ as unreliable and excluded them from our analyses. Demographic and lifestyle variables, including daily coffee (regular and decaffeinated) and tea consumption, were evaluated for their association with NMSC by $\chi^{2}$ tests. Sample size for each analysis differed because of missing data values. Other sources of caffeine intake (e.g. colas) were not included in the regression model because relevant information was not available. Stepwise logistic regression analysis was used to construct a dose-response model for caffeinated coffee's association with NMSG. In order to avoid the spurious choice of variables in the model as a consequence of the large sample size, we used a criteria of a significant $F$ value to enter and another $F$ value to remove from the analyses of 0.01 and 0.05 , respectively. The data were analyzed using the SPSS (version 11.0) statistical package for Windows (SPSS Inc., Chicago, Illinois, USA).

\section{Results}

A total of 93676 women of diverse ethnic backgrounds, $16.4 \%$ of whom were minority, provided baseline data. Overall prevalence of self-reported NMSC among all women in the study was $8.3 \%(n=7775)$. As the majority of women in this study were Caucasian $(83.6 \%)$, and nearly all cases (97.8\%) of self-reported NMSC occurred among these women, and because ethnicity was significantly related to the occurrence of NMSC $\left(\chi^{2}=1265.3\right.$, d.f. $\left.=5, P<0.001\right)$, we focused on this subgroup of 78013 women. Of these 78013 women, information with respect to self-reported NMSC was missing for 638 women. A further $467(0.6 \%)$ had missing data with respect to daily coffee drinking. Daily coffee consumption for the remaining 77373 women is shown in Table $1 ; 40.1 \%(n=31048)$ of these women only drank caffeinated coffee, $15.0 \% \quad(n=11597)$ only drank decaffeinated coffee, $16.5 \%(n=12759)$ drank both caffeinated and decaffeinated coffee, and $28.4 \%$ $(n=21969)$ reported drinking no coffee.

The relationship between demographic/life style variables and NMSC is shown in Table 2.

Latitude of residence was significantly associated with NMSC; the highest prevalence occurred among women living in the southernmost latitude (12.6\%) and the lowest in the northernmost latitude (7.6\%). Higher BMI $(\geq 25)$ was also significantly associated with NMSC. The higher the education and income levels, the higher the prevalence of NMSG. Smoking and alcohol consumption were both significantly associated with NMSC. Past or current users of menopausal hormone replacement therapy had a higher prevalence of NMSC than nonusers, but only the differences between past users or current users, and never users were significant $(P<0.001$ for each). Physical activity was positively associated with the prevalence of NMSC whereas percentage of daily dietary calories from fat was negatively related. Beta-carotene intake was significantly related to NMSC but the association with NMSC was not linear.

The relationship between daily caffeinated coffee consumption and NMSC is shown in Table 3. Drinking caffeinated coffee was associated with a decreased prevalence of self-reported NMSC compared with nondrinkers (9.1 vs. $10.2 \%$, respectively). This association 
Table 1 Demographic characteristics of Caucasian women with and without skin cancer ${ }^{\mathrm{a}}$

\begin{tabular}{|c|c|c|c|c|c|c|}
\hline \multirow[b]{2}{*}{ Variable } & \multirow[b]{2}{*}{ Levels } & \multicolumn{2}{|c|}{ Noncases $(n=69893)$} & \multicolumn{2}{|c|}{ Cases $(n=7482)$} & \multirow[b]{2}{*}{$\chi^{2}$ (d.f.) $P$} \\
\hline & & $n$ & Percentage & $n$ & Percentage & \\
\hline \multirow[t]{4}{*}{ Age group at screening (years) } & $50-59$ & 21907 & 31.3 & 1515 & 20.2 & $535.5(2)<0.001$ \\
\hline & $60-69$ & 30995 & 44.3 & 3413 & 45.6 & \\
\hline & $70-79$ & 16991 & 24.3 & 2554 & 34.1 & \\
\hline & Missing & 0 & & 0 & & \\
\hline \multirow[t]{5}{*}{ Education } & $<12$ years & 2349 & 3.4 & 168 & 2.3 & 177.0 (3) $<0.001$ \\
\hline & HS/GED & 11736 & 16.9 & 946 & 7.5 & \\
\hline & School after HS & 25467 & 36.7 & 2606 & 35.1 & \\
\hline & $\begin{array}{c}\text { College degree or } \\
\text { higher }\end{array}$ & 29828 & 43.0 & 3714 & 50.0 & \\
\hline & Missing & 513 & 0.7 & 48 & 0.6 & \\
\hline \multirow[t]{4}{*}{ Income category } & $<\$ 20000$ & 8936 & 12.8 & 838 & 11.2 & $15.2(2)<0.001$ \\
\hline & $\$ 20000-49999$ & 28535 & 40.8 & 3073 & 41.1 & \\
\hline & $\$ 50000$ & 27576 & 39.5 & 3026 & 40.4 & \\
\hline & Missing & 4846 & 6.9 & 545 & 7.3 & \\
\hline \multirow[t]{3}{*}{ Body mass index } & $<25$ & 29252 & 41.9 & 3516 & 47.0 & $71.9(1)<0.001$ \\
\hline & $>25$ & 39822 & 57.0 & 3889 & 52.0 & \\
\hline & Missing & 819 & 1.2 & 77 & 1.0 & \\
\hline \multirow[t]{4}{*}{ Menopausal hormone therapy } & Never used & 27091 & 38.8 & 2767 & 37.0 & $27.3(2)<0.001$ \\
\hline & Past user & 10435 & 14.9 & 1281 & 17.1 & \\
\hline & Current user & 32317 & 46.2 & 3426 & 45.8 & \\
\hline & Missing & 50 & 0.1 & 8 & 0.1 & \\
\hline \multirow[t]{4}{*}{ Region by latitude } & Southern $<35^{\circ} \mathrm{N}$ & 19215 & 27.5 & 2763 & 36.9 & $372.5(2)<0.001$ \\
\hline & Middle $35-40^{\circ} \mathrm{N}$ & 19600 & 28.0 & 2150 & 28.7 & \\
\hline & Northern $>40^{\circ} \mathrm{N}$ & 31078 & 44.5 & 2569 & 34.3 & \\
\hline & Missing & 0 & & 0 & & \\
\hline \multirow[t]{4}{*}{ Smoking status } & Never & 34318 & 49.1 & 3609 & 48.2 & $7.5(2)<0.001$ \\
\hline & Past & 30666 & 43.9 & 3391 & 45.3 & \\
\hline & Current & 4075 & 5.8 & 397 & 5.3 & \\
\hline & Missing & 834 & 1.2 & 85 & 1.1 & \\
\hline \multirow[t]{5}{*}{ Alcohol } & Nondrinker & 6282 & 9.0 & 623 & 8.3 & 17.4 (3) $<0.001$ \\
\hline & Past drinker & 11868 & 17.0 & 1214 & 16.2 & \\
\hline & $<7$ drinks per week & 41686 & 59.6 & 4452 & 59.5 & \\
\hline & $7+$ drinks per week & 9723 & 13.9 & 1158 & 15.5 & \\
\hline & Missing & 334 & 0.5 & 35 & 0.5 & \\
\hline \multirow[t]{5}{*}{ Total calories from fat (\%) } & $<30$ & 31969 & 45.7 & 3560 & 47.6 & 22.1 (3) $<0.001$ \\
\hline & $30-35$ & 14161 & 20.3 & 1578 & 21.1 & \\
\hline & $35-40$ & 10889 & 15.6 & 1143 & 15.3 & \\
\hline & $>40$ & 10776 & 15.4 & 1016 & 13.6 & \\
\hline & Missing & 2078 & 3.0 & 187 & 2.5 & \\
\hline Beta carotene (log $\mu \mathrm{g}$ as percentiles) & $25 \%(<2296)$ & 17144 & 24.5 & 1590 & 21.3 & 68.6 (3) $<0.001$ \\
\hline & $50 \%(2296-3479)$ & 16866 & 24.1 & 1739 & 23.2 & \\
\hline & $75 \%(3480-5275)$ & 16876 & 24.1 & 1866 & 25.2 & \\
\hline & $100 \%(>5275)$ & 16854 & 24.1 & 2085 & 27.6 & \\
\hline & Missing & 2153 & 3.1 & 202 & 2.7 & \\
\hline Physical activity total METs per week & $25 \%(<3.67)$ & 17518 & 25.1 & 1642 & 21.9 & $41.4(3)<0.001$ \\
\hline & $50 \%(3.68-10.5)$ & 18219 & 26.1 & 1970 & 26.3 & \\
\hline & $75 \%(10.51-20.5)$ & 16517 & 23.6 & 1844 & 24.6 & \\
\hline & $100 \%(>20.5)$ & 17034 & 24.4 & 1979 & 26.5 & \\
\hline & Missing & 605 & 0.9 & 47 & 0.6 & \\
\hline Current healthcare provider & Yes & 66204 & 94.7 & 7154 & 95.6 & $15.7(1)<0.001$ \\
\hline & No & 3130 & 4.5 & 261 & 3.5 & \\
\hline & Missing & 559 & 0.8 & 67 & 0.9 & \\
\hline Marital status & Never married & 3110 & 4.4 & 336 & 4.5 & $7.23(2)<0.03$ \\
\hline & Divorced/separated & 21555 & 30.8 & 2417 & 32.3 & \\
\hline & Presently married & 44959 & 64.3 & 4697 & 62.6 & \\
\hline & Missing & 269 & 0.4 & 32 & 0.4 & \\
\hline Daily coffee drinking & None & 19723 & 28.2 & 2246 & 30.0 & $31.3(3)<0.001$ \\
\hline & Caffeinated only & 28243 & 40.4 & 2805 & 37.5 & \\
\hline & Decaffeinated only & 10372 & 14.8 & 1225 & 16.4 & \\
\hline & Both & 11553 & 16.5 & 1206 & 16.4 & \\
\hline Daily tea drinking & Yes & 18360 & 26.8 & 2029 & 27.1 & 2.6 (1) NS \\
\hline & No & 50999 & 72.4 & 5392 & 72.1 & \\
\hline & Missing & 534 & 0.8 & 61 & 0.8 & \\
\hline
\end{tabular}

${ }^{\text {a } C h i-s q u a r e d ~ d i d ~ n o t ~ i n c l u d e ~ ' m i s s i n g ' ~ d a t a ~ c a t e g o r i e s . ~ M E T s, ~ m e t a b o l i c ~ e q u i v a l e n t ~ t a s k s . ~}$

was systematically related to the level of consumption. For those drinking six or more cups of caffeinated coffee per day, prevalence decreased from 10.3 to $6.7 \%$, compared with nondrinkers, a $35 \%$ decrease in prevalence.
After adjusting for covariates, drinking caffeinated coffee was associated with a dose-related decreased prevalence of self-reported NMSC among Caucasian women in the regression model. A polynomial contrast analysis indicated that the linear trend for the relationship between 
Table 2 Demographic/lifestyle variables and risk of nonmelanoma skin cancer

\begin{tabular}{|c|c|c|c|c|c|}
\hline \multirow[b]{2}{*}{ Variable } & \multirow[b]{2}{*}{ Category } & \multicolumn{2}{|c|}{ Crude OR } & \multicolumn{2}{|c|}{ Unadjusted OR } \\
\hline & & OR & $95 \% \mathrm{Cl}$ & OR & $95 \% \mathrm{Cl}$ \\
\hline \multirow[t]{3}{*}{ Age (years) } & $50-59$ & - & - & - & - \\
\hline & $60-69$ & 1.05 & $(1.01-1.10)$ & 1.05 & $(1.02-1.09)$ \\
\hline & $70-79$ & 1.45 & $(1.38-1.52)$ & 1.44 & $(1.39-1.49)$ \\
\hline \multirow[t]{4}{*}{ Alcohol } & Nondrinker & & & & \\
\hline & Past drinker & 1.09 & $(0.94-1.27)$ & 1.03 & $(0.93-1.14)$ \\
\hline & $<7$ drinks per week & 1.24 & $(1.09-1.42)$ & 1.08 & $(0.99-1.18)$ \\
\hline & $>7$ drinks per week & 1.38 & $(1.19-1.60)$ & 1.20 & $(1.08-1.33)$ \\
\hline \multirow[t]{4}{*}{ Education } & $<12$ years & & & & \\
\hline & High school degree & 1.31 & $(1.03-1.65)$ & 1.13 & $(0.95-1.34)$ \\
\hline & After high school & 1.59 & $(1.27-2.00)$ & 1.43 & $(1.22-1.68)$ \\
\hline & College degree & 1.90 & (1.52-2.39) & 1.74 & $(1.48-2.04)$ \\
\hline \multirow[t]{3}{*}{ Hormone replacement therapy status } & Never used & & & & \\
\hline & Past user & 1.17 & $(1.07-1.28)$ & 1.20 & $(1.12-1.29)$ \\
\hline & Current user & 1.04 & $(0.97-1.11)$ & 1.04 & $(0.99-1.09)$ \\
\hline \multirow[t]{3}{*}{ Region } & Southern & & & & \\
\hline & Middle & 0.99 & $(0.95-1.04)$ & 1.00 & $(0.97-1.04)$ \\
\hline & Northern & 0.76 & $(0.73-0.80)$ & 0.76 & $(0.73-0.78)$ \\
\hline \multirow[t]{2}{*}{ Body mass index } & $<25$ & & & & \\
\hline & $\geq 25$ & 0.89 & $(0.83-0.94)$ & 0.81 & $(0.77-0.85)$ \\
\hline \multirow[t]{4}{*}{ Calories from fat $(\%)$} & $<30$ & & & & \\
\hline & $30-35$ & 1.03 & $(0.94-1.13)$ & 1.00 & $(0.94-1.06)$ \\
\hline & $35.1-40$ & 1.05 & $(0.96-1.15)$ & 0.94 & $(0.88-1.01)$ \\
\hline & $>40$ & 1.19 & $(1.08-1.30)$ & 0.85 & $(0.79-0.91)$ \\
\hline
\end{tabular}

OR, odds ratio; $\mathrm{Cl}$, confidence interval.

Table 3 Daily caffeinated coffee drinking and risk of nonmelanoma skin cancer among Caucasian women (77 373)

\begin{tabular}{lcccccc}
\hline Cups & $n$ & Percentage & Percentage with skin cancer & Odds ratio $^{a}$ & $95 \%$ Confidence interval $^{\text {Unadjusted odds ratio }}{ }^{\mathrm{b}}$ \\
\hline $0^{\mathrm{c}}$ & 33568 & 43.4 & 10.3 & 1.0 & - & - \\
1 & 12584 & 16.3 & 10.2 & 0.96 & $(0.89-1.03)$ & $0.99(0.92-1.05)$ \\
$2-3$ & 23133 & 29.9 & 9.1 & 0.87 & $(0.81-0.92)$ & $0.87(0.82-0.92)$ \\
$4-5$ & 6352 & 8.2 & 8.1 & 0.83 & $(0.75-0.92)$ & $0.76(0.69-0.84)$ \\
6 or more & 1738 & 2.2 & 6.7 & 0.70 & $(0.60-0.88)$ & $0.63(0.52-0.76)$ \\
Total & 77375 & & 9.7 & & & \\
\hline
\end{tabular}

${ }^{a}$ Odds ratio variables included in stepwise regression model: age at screening, alcohol consumption, smoking, income, region of residence by latitude, education, menopausal hormone therapy, body mass index, and $\beta$-carotene intake.

bUnadjusted odds ratio based on cups of regular coffee as the only predictor in the model.

${ }^{\mathrm{c}}$ Drinks either no coffee or decaffeinated coffee only.

Table 4 Daily intake of decaffeinated coffee and tea and unadjusted odds ratio (OR) of nonmelanoma skin cancer (NMSC) risk

\begin{tabular}{|c|c|c|c|c|c|c|c|c|c|c|c|}
\hline \multicolumn{6}{|c|}{ Decaffeinated coffee } & \multicolumn{6}{|c|}{ Tea } \\
\hline Cups & $n$ & Percentage & $\begin{array}{l}\text { Percentage } \\
\text { NMSC }\end{array}$ & OR & $95 \% \mathrm{Cl}$ & Cups & $n$ & Percentage & $\begin{array}{l}\text { Percentage } \\
\text { NMSC }\end{array}$ & OR & $95 \% \mathrm{Cl}$ \\
\hline 0 & 29777 & 54.3 & 9.1 & - & - & 0 & 56391 & 73.9 & 9.6 & - & - \\
\hline 1 & 11537 & 21.0 & 10.0 & 1.12 & $1.04-1.20$ & 1 & 9653 & 12.6 & 10.1 & 1.06 & $0.99-1.14$ \\
\hline $2-3$ & 10803 & 19.7 & 10.1 & 1.13 & $1.05-1.22$ & $2-3$ & 8105 & 10.6 & 11.0 & 1.05 & $0.97-1.14$ \\
\hline $4-5$ & 2246 & 4.1 & 8.8 & 0.96 & $0.83-1.12$ & $4-5$ & 1683 & 2.2 & 9.1 & 0.95 & $0.80-1.12$ \\
\hline$>6$ & 483 & 0.9 & 9.7 & 1.08 & $0.80-1.46$ & $>6$ & 488 & 0.6 & 8.2 & 0.84 & $0.61-1.17$ \\
\hline Total & 54846 & & 9.5 & & & Total & 76320 & & 9.7 & & \\
\hline
\end{tabular}

$\mathrm{Cl}$, confidence interval.

caffeinated coffee consumption and the risk of NMSC was statistically significant $(P<0.001)$.

As chronic cumulative exposure to solar ultraviolet radiation is the most important factor associated with NMSC (Taylor and Sober, 1996), we also tested for an interaction between cups of caffeinated coffee and latitude, for risk of NMSC. The interaction was not statistically significant.
We also conducted a subgroup analysis of the relationship between coffee consumption and NMSC stratifying for histories of other cancers. The relationship between caffeinated coffee consumption and NMSG was not significant for women with a history of cancer other than NMSC. A significant dose-response relationship, however, was still evident for those women without a history of other cancers. The odds ratio for six or more for the latter cups was 0.70 (confidence interval: $0.56-0.89, P<0.001$ ). 
Although statistically significant as a sole factor, consumption of decaffeinated coffee or tea was not significantly associated with NMSC for Caucasian women in the logistic regression (see Table 4).

\section{Discussion}

Nonmelanoma skin cancer is the most common type of skin cancer among Caucasians in the United States (Strom and Yamamura, 1997). We focused on caffeinated coffee consumption in this study, because experiments in animals have found that caffeine reduced the occurrence of skin cancers in mice exposed to relatively large amounts of ultraviolet radiation (Wang et al., 1991, 1992, 1994; Huang et al., 1997), and because of corroborative reports from small-scale epidemiological studies that coffee had a small but significant protective association with NMSC in humans (Jacobsen et al., 1986; Corona et al., 2001). Although cola and tea drinks are another source of caffeine intake, the questionnaire did not distinguish between different sodas or teas, which differ in the amounts of caffeine they contain, or assess patterns of soda intake. A recent study also indicated that daily caffeine intake from soft drinks for women 55-64 years old is less than $10 \%$ and for women 65 years of age and older, less than $4 \%$ (Frary et al., 2005).

Our cross-sectional epidemiological study examined the association between daily coffee consumption and NMSC in a relatively large sample of postmenopausal women, 50 years of age or older, using baseline data at time of initial entry to the WHI Observational Study, and took into account many of the potentially confounding variables previously found to be associated with cancer (Schottenfeld, 1996; Rosenberg et al., 2004). As nearly all the instances of NMSC occurred in Caucasian women, we focused on this group. While basal cell carcinomas are the primary type of NMSCs among Caucasians in the United States (Tavani and LaVecchia, 2000), the other common condition included in this type of skin cancer is cutaneous squamous cell carcinoma (Marks, 1996). Unfortunately, the data available for our study did not include information with respect to the different types of NMSCs. No reason, however, exists to suspect that the women in this study differed from the general population in typology.

As previously reported, we found that residential sunlight exposure was related to the prevalence of NMSC (Webb et al., 1988; Taylor and Sober, 1996; Strom and Yamamura, 1997). Prevalence was highest for women living in the southernmost latitudes and lowest for those in the northernmost latitudes. Greater body weight (BMI $>25 \mathrm{~kg} / \mathrm{m}^{2}$ ) and decreased physical activity, on the other hand, were significantly associated with a reduced prevalence of NMSC. One likely explanation is that women who are overweight and are less active do not spend as much time outdoors and therefore have less exposure to ultraviolet radiation. We did not, however, find a significant interaction between coffee consumption and latitude on NMSC. Higher income and education were also both related to a higher prevalence of NMSC, possibly because they may be associated with more outdoor leisure activity and vacationing in sunny climates for those individuals. Menopausal hormone therapy was also associated with a higher prevalence of NMSC. Prevalence of NMSC was higher for women with current healthcare providers, suggesting that the overall prevalence of NMSC is underestimated.

Diet and body weight are known to influence the occurrence of cancers (Black, 1998; Riboli, 2001; Kaaks et al., 2002), but we did not find such an association with NMSC. We did, however, corroborate a previous report of the association between increased alcohol consumption and past smoking with a higher prevalence of NMSC (Aubry and MacGibbon, 1985; Grodstein et al., 1995; Veierod et al., 1997; De Hertog et al., 2001). We also found that past smoking was associated with an increased prevalence of NMSC, although current smokers had the lowest rate of NMSC.

Daily consumption of caffeinated coffee was associated with a dose-related decreased prevalence on NMSC of nearly $5 \%$ for each cup. Daily consumption of six or more cups of caffeinated coffee was associated with a decreased prevalence of $31 \%$. Daily consumption of decaffeinated coffee or tea, on the other hand, was not related to a significantly altered prevalence of NMSC.

One of the strengths of this study was that it included a relatively large population, enabling us to evaluate daily coffee consumption while controlling for other potentially confounding variables. This, however, was also a crosssectional study, and therefore the temporal relationship between coffee consumption and NMSC could not be elucidated from these data. It is unlikely, however, that women began drinking coffee only after a diagnosis of NMSC. Several limitations are also associated with this study. One is the potential recruitment bias associated with any volunteer study. It is possible, for instance, that women with cancer or concerned about cancer were overrepresented. On the other hand, healthy women, concerned about cancer, may be over-represented.

Recall bias is another concern. Although the current study relied on self-report for a history of NMSC, recent studies suggest that self reported NMSC has a high degree of accuracy (Ming et al., 2004). Recall bias also has to be considered with respect to the amount of coffee and tea consumption. Assessment error is inherent in questionnaire-based dietary information, so that estimated relationships are not objective. As diet likely changed for 
many women in the years prior to assessment, the dietary information recorded at enrollment may not reflect general patterns of diet over the lifespan. Denial and under-reporting also has to be considered in the context of smoking and alcohol use (Abel, 1998). We, however, are not aware of any data suggesting differential underreporting of either smoking or alcohol use in women with and without NMSC. Information about coffee and tea use may also be problematic as women were asked to recall their levels of daily consumption at the time of enrollment and consumption levels may have not been similar at the time women were diagnosed with skin cancer.

Despite these caveats, the decreased prevalence in NMSC associated with consumption of daily consumption of caffeinated coffee that we observed was doserelated and consistent with other studies. Among the possible explanations for caffeine's protective effect on NMSC that have been suggested is an antioxidant effect (Kuo, 1997; Trevisanato and Kim, 2000) and/or inhibition of DNA synthesis and cell division, making cells less susceptible to carcinogenesis (Timson, 1997).

We conclude that daily caffeinated coffee consumption is associated with a dose-related decreased prevalence of NMSC in Caucasian women. Ideally, the observations reported here and our conclusion should be explored in future prospective studies.

\section{Acknowledgements}

The WHI program is funded by the National Heart, Lung and Blood Institute, US Department of Health and Human Services.

\section{References}

Abel EL (1998). Fetal alcohol abuse syndrome. New York: Plenum Press.

Aubry F, MacGibbon B (1985). Risk factors of squamous cell carcinoma of the skin: a case-control study in the Montreal region. Cancer 55:907-911.

Black HS (1998). Influence of dietary factors on actinically-induced skin cancer. Mutat Res 422:185-190.

Corona R, Dogliotti E, D'Errico M, Sera F, Levarone I, Baliva G, et al. (2001). Risk factors for basal cell carcinoma in a Mediterranean population: role of recreational sun exposure early in life. Arch Dermato/ 37:1162-1168.

De Hertog SAE, Wensveen CAH, Bastiaens MT, Kiehich CJ, Berkhout MJP, Westendorp RGJ, et al. (2001). Relation between smoking and skin cancer. J Clin Oncol 19:231-238.

Frary CF, Johnson RK, Wang MQ (2005). Food sources and intakes of caffeine in the diets of persons in the United States. J Am Diet Assoc 105:110-113.

Grodstein F, Speizer FE, Hunter DJ (1995). A prospective study of incident squamous cell carcinoma of the skin in the nurses' health study. J Natl Cancer Inst 87:1061-1066.

Huang M-T, Xie J-G, Wang ZY, Ho CT, Lou YR (1997). Carcinogenesis in SKH-1 mice: demonstration of caffeine as a biologically important constituent of tea. Cancer Res 57:2623-2629.

Jacobsen BK, Bjelke R, Kvale G, Heuch I (1986). Coffee drinking, mortality, and cancer incidence: results from a Norwegian prospective study. J Nat/ Cancer Invest 76:823-834.

Johnson ML, Johnson KG, Engel A (1984). Prevalence, morbidity, and cost of dermatologic diseases. J Am Acad Dermatol 11:930-936.

Kaaks R, Lukanova A, Kurzer MS (2002). Obesity, endogenous hormones, and endometrial cancer risk. A synthetic review. Cancer Epidemiol Biomarkers Prevent 11:1531-1543.
Kuo SM (1997). Dietary flavonoid and cancer prevention: evidence and potential mechanism. Crit Rev Oncol 8:47-69.

Langer RD, White E, Lewis CE, Kotchen J, Hendrix S, Trevisan M (2003). The Women's Health Initiative Observational Study: baseline characteristics of participants and reliability of baseline measures. Ann Epidemiol 13: S107-S121.

Marks R (1996). Squamous cell carcinoma. Lancet 347:735-738.

Michels KB, Holmberg L, Bergkvist L, Wolk A (2002). Coffee, tea, and caffeine consumption and breast cancer incidence in a cohort of Swedish women. Ann Epidemiol 12:21-26.

Ming ME, Ross R, Levy RM, Ole J, Hoffstad MA, Filip J, et al. (2004). Validity of patient self reported history of skin cancer. Arch Dermatol 140:730-735.

Riboli E (2001). The European prospective investigation into cancer and nutrition (EPIC): plans and progress. J Nutr 131:170S-175S.

Rosenberg CA, Greenland P, Khandekar J, Loar A, Ascensao J, Lopez AM (2004). Association of nonmelanoma skin cancer with second malignancy. The Women's Health Initiative Observational Study. Cancer 100:130-138.

Schottenfeld D (1996). Basal-cell carcinoma of the skin: a harbinger of cutanenous and noncutaneous multiple primary cancer (editorial). Ann Intern Med 125:852-854.

Strom SS, Yamamura Y (1997). Epidemiology of nonmelanoma skin cancer. Clin Plast Surg 24:627-636.

Tavani A, LaVecchia C (2000). Coffee and cancer: a review of epidemiological studies, 1990-1999. Eur J Cancer Prevent 9:241-256.

Taylor CR, Sober AJ (1996). Sun exposure and skin disease. Ann Rev Med 47:181-191.

The Women's Health Initiative (WHI) Study Group (1998). Design of the Women's Health Initiative clinical trial and observational study. Control Clin Trials 19:61-109.

Timson J (1997). Caffeine. Mutat Res 47:1-52.

Trevisanato S, Kim YI (2000). Tea and health. Nutr Rev 58:1-10.

Veierod MB, Thelle DS, Laake P (1997). Diet and risk of cutaneous malignant melanoma: a prospective study of 50757 Norwegian men and women. Int $J$ Cancer 71:600-604.

Von Domarus H, Stevens PJ (1984). Metastatic basal cell carcinoma: report of five cases and review of 170 cases in the literature. J Am Acad Dermatol 10:1043-1060.

Wang ZY, Agarwal R, Bickers DR, Mukhtar H (1991). Protection against ultraviolet $B$ radiation-induced photocarcinogenesis in hairless mice by green tea polyphenols. Carcinogenesis 12:1527-1530.

Wang ZY, Huang M-T, Ferraro T, Wong CQ, Lou YR, Reuhl K, et al. (1992). Inhibitory effect of green tea in drinking water on tumorigenesis by ultraviolet light and 12-O-tetradecanolylphorbol-13-acetate in the skin of SKH-1 mice. Cancer Res 52:1162-1170.

Wang ZY, Huang MT, Lou Y-R, Xie JG, Reuhl KR, Newmark HL, et al. (1994). Inhibitory effects of black tea, green tea, decaffeinated black tea, and decaffeinated green tea on ultraviolet $\mathrm{B}$ light-induced skin carcinogenesis in 7,12-dimethylbenz(a)anthracene-initiated $\mathrm{SKH}-1$ mice. Cancer Res 54: 3428-3435.

Webb AR, Kline L, Holick MF (1988). Influence of season and latitude on the cutaneous synthesis of vitamin D3: exposure to winter sunlight in Boston and Edmonton will not promote vitamin D3 synthesis in human skin. J Clin Endocrinol Metab 667:373-378.

\section{Appendix}

\section{Short list of Women's Health Initiative investigators Program office}

National Heart, Lung, and Blood Institute, Bethesda, Maryland: Barbara Alving, Jacques Rossouw, Linda Pottern.

\section{Clinical coordinating center}

Fred Hutchinson Cancer Research Center, Seattle, Washington: Ross Prentice, Garnet Anderson, Andrea LaCroix, Charles L. Kooperberg, Ruth E. Patterson, Anne McTiernan; Wake Forest University School of Medicine, Winston-Salem, North Carolina: Sally Shumaker; Medical Research Laboratories, Highland Heights, Kentucky: Evan Stein; University of California at San Francisco, San Francisco, California: Steven Cummings. 


\section{Clinical centers}

Albert Einstein College of Medicine, Bronx, New York: Sylvia Wassertheil-Smoller; Baylor College of Medicine, Houston, Texas: Jennifer Hays; Brigham and Women's Hospital, Harvard Medical School, Boston, Massachusetts: JoAnn Manson; Brown University, Providence, Rhode Island: Annlouise R. Assaf; Emory University, Atlanta, Georgia: Lawrence Phillips; Fred Hutchinson Cancer Research Center, Seattle, Washington: Shirley Beresford; George Washington University Medical Center, Washington, District of Columbia: Judith Hsia; Harbor-UCLA Research and Education Institute, Torrance, California: Rowan Chlebowski; Kaiser Permanente Center for Health Research, Portland, Oregon: Evelyn Whitlock; Kaiser Permanente Division of Research, Oakland, California: Bette Caan; Medical College of Wisconsin, Milwaukee, Wisconsin: Jane Morley Kotchen; MedStar Research Institute/Howard University, Washington, District of Columbia: Barbara V. Howard; Northwestern University, Chicago/Evanston, Illinois: Linda Van Horn; Rush-Presbyterian St. Luke's Medical Center, Chicago, Illinois: Henry Black; Stanford Prevention Research Center, Stanford, California: Marcia L. Stefanick; State University of New York at Stony Brook, Stony Brook, New York: Dorothy Lane; The Ohio State University, Columbus, Ohio: Rebecca Jackson; University of Alabama at Birmingham, Birmingham, Alabama: Cora E. Lewis; University of Arizona, Tucson/Phoenix, Arizona: Tamsen Bassford; University at Buffalo, Buffalo, New York:
Jean Wactawski-Wende; University of California at Davis, Sacramento, California: John Robbins; University of California at Irvine, Orange, California: Allan Hubbell; University of California at Los Angeles, Los Angeles, California: Howard Judd; University of California at San Diego, LaJolla/Chula Vista, California: Robert D. Langer; University of Cincinnati, Cincinnati, Ohio: Margery Gass; University of Florida, Gainesville/Jacksonville, Florida: Marian Limacher; University of Hawaii, Honolulu, Hawaii: David Curb; University of Iowa, Iowa City/ Davenport, Iowa: Robert Wallace; University of Massachusetts/Fallon Clinic, Worcester, Massachusetts: Judith Ockene; University of Medicine and Dentistry of New Jersey, Newark, New Jersey: Norman Lasser; University of Miami, Miami, Florida: Mary Jo O'Sullivan; University of Minnesota, Minneapolis, Minnesota: Karen Margolis; University of Nevada, Reno, Nevada: Robert Brunner; University of North Carolina, Chapel Hill, North Carolina: Gerardo Heiss; University of Pittsburgh, Pittsburgh, Pennsylvania: Lewis Kuller; University of Tennessee, Memphis, Tennessee: Karen G. Johnson; University of Texas Health Science Center, San Antonio, Texas: Robert Brzyski; University of Wisconsin, Madison, Wisconsin: Gloria E. Sarto; Wake Forest University School of Medicine, Winston-Salem, North Carolina: Denise Bonds; Wayne State University School of Medicine/ Hutzel Hospital, Detroit, Michigan: Susan Hendrix. 